\title{
Dawn chorus interpretation differs when using songs or calls: the Dupont's Lark Chersophilus duponti case
}

\author{
Cristian Pérez-Granados ${ }^{\text {Corresp., }}{ }^{1,2}{ }^{\text {, }}$ Tomasz S Osiejuk ${ }^{3}$, Germán M López-Iborra ${ }^{1}$ \\ 1 Ecology Department/Multidisciplinary Institute for Environmental Studies “Ramón Margalef"., Universidad de Alicante, Alicante, Spain \\ 2 Present address. Terrestrial Ecology Group (TEG-UAM), Department of Ecology, Universidad Autónoma de Madrid, Madrid, Spain \\ 3 Department of Behavioural Ecology, Institute of Environmental Biology, Faculty of Biology, Umultowska 89, 61614., Adam Mickiewicz University of \\ Poznan, Poznan, Poland \\ Corresponding Author: Cristian Pérez-Granados \\ Email address: cristian.perez@ua.es
}

Background: Territorial songbirds vocalise intensively before sunrise and then decrease their vocal activity. This creates a communication network that disseminates essential information for both males and females. The function of dawn chorus in birds has been frequently interpreted according to seasonal variation of singing as the breeding season advances, but potential differences in seasonal variation of song and calls for the same species have not been taken into account. Methods: We chose Dupont's Lark as a model species to study whether the seasonal pattern of dawn chorus differs between singing and calling activity, because in this species most daily songs and calls are uttered at dawn. We registered vocal activity of Dupont's Lark before and around dawn in three different populations, through repeated sampling over the entire breeding season of two consecutive years. Results: We found that dawn singing parameters remained constant or presented an increasing trend while dawn calling activity decreased as breeding season advanced. We also found different daily patterns for singing and calling, with birds calling mostly during the first 30 minutes of dawn choruses and singing peaking afterwards. Discussion: The different time patterns of songs and calls may indicate that they serve diverse functions at dawn in the Dupont's Lark. Relaxation of dawn calling activity after the first month of the breeding season would suggest that dawn calling may be mainly related to mate attraction, while constant dawn singing throughout the breeding period would support a relationship of dawn calling to territorial defence. Our study highlights that the type of vocalisation used is an important factor to consider in further research on dawn choruses, since results may differ depending on whether calls or songs are analysed. 
1 Dawn chorus interpretation differs when using songs or calls: the Dupont's Lark Chersophilus 2 duponti case.

3

4 Cristian Pérez-Granados ${ }^{1 \# *}$, Tomasz S. Osiejuk² \& Germán M. López-Iborra ${ }^{1}$. 5

6

$7{ }^{1}$ Ecology Department/Multidisciplinary Institute for Environmental Studies "Ramón Margalef”.

8 Universidad de Alicante, PO Box 99, 03080. Alicante, Spain.

$9{ }^{2}$ Department of Behavioural Ecology, Institute of Environmental Biology, Faculty of Biology,

10 Adam Mickiewicz University, Umultowska 89, 61614. Poznań, Poland.

11

12 \# Present address. Terrestrial Ecology Group (TEG-UAM), Department of Ecology, Universidad

13 Autónoma de Madrid. C/Darwin, 2, 28049. Madrid, Spain.

$14{ }^{*}$ Corresponding author: Cristian Pérez-Granados. E-mail address: cristian.perez@ua.es. Tel: +34

15 (914978271). Fax: +34 (914978001). 


\section{Abstract}

24 Background: Territorial songbirds vocalise intensively before sunrise and then decrease their vocal activity. This creates a communication network that disseminates essential information for both males and females. The function of dawn chorus in birds has been frequently interpreted according to seasonal variation of singing as the breeding season advances, but potential differences in seasonal variation of song and calls for the same species have not been taken into account. Methods: We chose Dupont's Lark as a model species to study whether the seasonal pattern of dawn chorus differs between singing and calling activity, because in this species most daily songs and calls are uttered at dawn. We registered vocal activity of Dupont's Lark before and around dawn in three different populations, through repeated sampling over the entire breeding season of two consecutive years. Results: We found that dawn singing parameters remained constant or presented an increasing trend while dawn calling activity decreased as breeding season advanced. We also found different daily patterns for singing and calling, with birds calling mostly during the first 30 minutes of dawn choruses and singing peaking afterwards. Discussion: The different time patterns of songs and calls may indicate that they serve diverse functions at dawn in the Dupont's Lark. Relaxation of dawn calling activity after the first month of the breeding season would suggest that dawn calling may be mainly related to mate attraction, while constant dawn singing throughout the breeding period would support a relationship of dawn calling to territorial defence. Our study highlights that the type of vocalisation used is an important factor to consider in further research on dawn choruses, since results may differ depending on whether calls or songs are analysed. 
47

48

49

50

51

52

53

54

\section{Introduction}

Dawn chorus occurs when birds, usually males, begin to sing before sunrise and then cease or decrease song activity for the rest of the day (Mace, 1987; Catchpole \& Slater, 2008, but see Garamszegi et al., 2006 and Webb et al., 2016 for female singing). It is a phenomenon found in many bird species and has been studied since the late 19th and early 20th centuries (e.g. Wright, 1912; Allen, 1913). Previous works have suggested that the dawn chorus may be regarded as a reliable signal of male quality (e.g. Grava et al., 2009; Marini et al., 2017). To understand dawn chorus in territorial birds, studies should account for: (1) the reason of the concentration of vocal activity at dawn, which has been explained by female behaviour, conditions for sound transmission and low foraging success at dawn, among others (Kacelnik \& Krebs, 1983; Kunc et al., 2005; Naguib et al., 2016), and (2) the function of the vocalisations uttered at dawn, which has been related to mate attraction (Eriksson \& Wallin, 1986; Poesel et al., 2006; Murphy et al., 2008) and to territorial defence and mate guarding (Møller, 1988; 1991; Amrhein and Erne, 2006), although the two functions can be complementary (Møller, 1991; Slagsvold et al., 1994).

Despite the prevalence of dawn-singing in birds and the numerous studies focused on that topic, its origin, evolution and causes remain unclear and seem to be context-dependent, differing among species, populations and studies (e.g. Staicer et al., 1996; Catchpole \& Slater, 2008; Zhang et al., 2016). This could be explained in part because researchers have indistinctly analysed or have even pooled calls and songs (Poesel et al., 2001; Grava et al., 2013; Stanley et al., 2016; Lee et al., 2017) to elucidate dawn chorus function (but see LaZerte et al., 2017). Nonetheless, the bulk of dawn chorus studies have been focused on singing activity (e.g. Gil et 
al., 1999; Amrheim et al., 2002; Liu, 2004). Although the distinction between calls and songs is not always clear-cut, in practice a given vocalisation can usually be readily classified as either a song or a call, and these classifications are commonly used in the birdsong literature (Zann, 1990; Wang et al., 2012). In oscines, hummingbirds and parrots, songs are defined as long, loud, complex, and learned spontaneous vocalisations whose function at dawn has usually been related to mate attraction, but also to compete with members of the same sex (Slagsvold et al., 1994; Catchpole \& Slater, 2008). Calls are usually described as shorter, simpler, less spontaneous and genetically determined vocalisations uttered throughout the year and that can be produced for a variety of reasons including maintaining group contact and signalling about food or danger, such as in cases of fight, threat or alarm (Marler, 2004; Catchpole \& Slater, 2008). The use of calls in dawn chorus has been little studied (but see LaZerte et al., 2017) and is not well understood. In some species, it has been suggested that calls are targeted to the current female (McCallum et al., 1999, Stowell et al., 2016). Thus, as the origin and evolution of the two types of vocalisations differ, the interpretation of dawn chorus function could vary according to the type considered.

In this study, we selected the Dupont's Lark (Chersophilus duponti) as a model to explore potential differences in the interpretation of dawn chorus when analysing songs or calls. We chose this species because it is a diurnal passerine with high vocal activity concentrated at dawn and because it utters a large number of both types of vocalisations during dawn choruses. There are several studies published about the song and the territorial call of this species, which provide good background for deeper analysis (Laiolo \& Tella, 2005; 2006; Laiolo, 2008; Laiolo et al., 2008; Pérez-Granados et al., 2016). All of these studies have assumed that only males sing and produce territorial calls, since females do not appear to utter long range vocalisations (Laiolo et al., 2007). Occasionally, Dupont's Lark males also produce warning calls (to repel intruders 
92 from their territories, Laiolo et al., 2005) and both sexes may utter distress calls, an ultimate

93 alarm signal given by individuals that are in predator risk (Laiolo et al., 2005, pers. obs).

94 Although some female larks are known to sing, such as the Eurasian Lark (Alauda arvensis) or

95 the Woodlark (Lullula arborea) (Garamszegi et al., 2006; Odom \& Benedict, 2018), there is no

96 evidence of Dupont's Lark females singing or uttering territorial or warning calls (Laiolo \&

97 Tella, 2005; Garamszegi et al., 2006; Laiolo, 2008; Laiolo et al., 2005, 2007, 2008; Barrero et

98 al., 2017; pers. obs.), despite the large number of bioacoustic studies focussed on the species and

99 the fact that hundreds of Dupont's Larks have been ringed and later resighted singing. Therefore,

100 in this study we considered that all monitored birds uttering songs or territorial calls were males.

101 We are aware that females are able to utter distress calls in the nest and during handling (pers.

102 obs.), but this type of vocalisation, as well as warning calls, were not included in our study and

103 we will refer to territorial calls simply as calls hereinafter.

104 In this paper, we aimed to investigate if singing and calling activity at dawn in the 105 Dupont's Lark have different seasonal patterns and to explore the consequences of using songs 106 or calls when interpreting dawn chorus function. For this purpose, we monitored the dawn 107 singing and calling activity of the Dupont's Lark during the breeding season in two consecutive 108 years. We hypothesised that if songs and calls have different functions, their seasonal pattern 109 throughout the breeding period would differ (Celis-Murillo et al., 2016). Vocalisation functions 110 cannot be demonstrated without experimental or more detailed observational analyses. However, 111 we assumed that the relationship between function and seasonal patterns of vocalisations in the 112 Dupont's Lark is similar to that described for other European passerines. Therefore, we expected 113 that Dupont's Lark singing or calling activity at dawn would decrease after pairing if they are 114 related to attracting females at that time, as described for other passerine species (e.g. Gil et al., 
115 1999; Amrheim et al., 2002; Liu, 2004; Celis-Murillo et al., 2016), but would remain constant if

116 they are related to territorial defence (e.g. Olinkiewicz \& Osiejuk, 2003; Kunc et al., 2005;

117 Amrhein \& Erne, 2006; Liu \& Kroodsma, 2007).

118

119 Material and methods

120 Study area

121 We conducted a field study from late March to early June in 2013 and 2014 in the three

122 largest Dupont's Lark populations in Valencia province (eastern Spain, Pérez-Granados \& 123 López-Iborra, 2013), where patch size and number of territorial males ranged between 193-200

124 ha and 10-19 males, respectively. Study sites were located at 1,000 $\mathrm{m}$ a.s.1. and the vegetation

125 was a shrub-steppe dominated by low shrub species (Thymus spp., Genista scorpius and 126 Rosmarinus officinalis). In all sites, there were some dispersed trees, especially pines Pinus spp. 127 and junipers (Junipers oxycedrus and J. communis). More information on the study area can be 128 found in Pérez-Granados et al. (2017a).

\section{Data collection}

130 We registered dawn singing and calling activity of Dupont's Lark males in three sites over two consecutive breeding seasons (years). Acoustic activity was measured through repeated 132 sampling over the entire breeding season from one fixed counting station per site and year. 133 Counting station location remained the same within a year but were separated by at least $500 \mathrm{~m}$ 134 among years (Fig. 1) in order to monitor two different areas within each site. This is also 135 expected to favour the monitoring of different males, since in the study area adult Dupont's Larks have been reported to move on average $100 \mathrm{~m}$ between breeding seasons (Pérez-Granados

137 \& López-Iborra, 2015). Likewise, only about half of the adult males survive between successive 
138 years (Laiolo et al., 2008), which would further decrease the probability of detecting the same

139 male in the two study years. Songs and calls were assigned to a specific male based on differing

140 direction and distance to the observer (Fig. 1). We only considered birds located within a $250 \mathrm{~m}$

141 radius from a station location that did not change their location during the survey (estimated

142 displacement less than $50 \mathrm{~m}$ ) to facilitate recognition. Distance from observer to vocalising bird

143 was determined upon acoustic clues and based on previous experience counting the species in the

144 study area (e.g. Pérez-Granados \& López-Iborra, 2013; 2017a). This wide radius was considered

145 given that the species' songs may be heard from long distances (Laiolo et al., 2007; Vögeli et al.,

146 2010). We monitored vocal activity of up to a maximum of four males per station and night, with

147 a mean $( \pm \mathrm{SD})$ number of $3.5 \pm 0.5$ males monitored per station/night.

148 Surveys were labelled as " $1,2,3,4,5$ or 6 ", following the order in which they were

149 conducted. In both years, the first survey was carried out between the $26^{\text {th }}$ and $31^{\text {st }}$ of March, and

150 successive surveys were carried out fortnightly from then until 14-16 of June. This period

151 corresponds to most of the breeding period of the species (Herranz et al., 1994; Pérez-Granados

152 et al., 2017b). The first two surveys (between late March and early April) correspond to the first

153 stage of the breeding time in the study area, when most females are building their nests and

154 laying first clutches. The third and fourth surveys (late April -early May) were carried out at the

155 peak of the breeding activity of the species (Herranz et al., 1994; Pérez-Granados et al., 2017b).

156 During this time of the season, breeding pairs are rearing their first clutch or, in some cases,

157 second or replacement clutches. The fifth and sixth surveys (late May-early June) were carried

158 out at the end of the breeding season, a time when some breeding pairs may have finished their

159 breeding period and a relaxation in territory defence may occur (Pérez-Granados et al., 2017b). 

at the station from 100-min before sunrise to ten minutes after dawn. The observer stood for 5

$162 \min$ in silence at each station before the study began. Daily times of sunrise at the geographic

163 location of the study area were obtained from the Spanish Ministry of Development 164 (http://astronomia.ign.es/web/guest/hora-salidas-y-puestas-de-sol). We divided the continuous 165 survey into 5-min intervals and registered the number of songs and calls uttered per male per 5166 min period. For each interval, we calculated song/call output as the total number of songs/calls 167 uttered per male. We also monitored song/call start and end time (5-min interval in which the 168 first and the last song or call were produced by any male each night) and performance time, measured as the total number of 5-min intervals that each bird was vocally active each night.

170 The song of the Dupont's Lark in the study area includes a mean of five discrete song types with no differences in male repertoire size among studied sites (Pérez-Granados et al., 172 2016). Song types are largely shared and repeated in the same order by neighbouring males and 173 end with a common sequence of the species' so-called 'whee-ur-wheee' (Cramp, 1988). We 174 considered the whole sequence of repeated song types as a unique song to facilitate data 175 collection and used the definite 'whee-ur-wheee' to define the boundary between one song and another. A sonogram of a typical sequence recorded in the study area can be found in Fig. 2 and a song recorded in the study area may be found in Pérez-Granados (XC216990, on www.xenocanto.org). Sonograms of the commonest song types in the three studied sites can be found in Pérez-Granados et al. (2016). Calls consist of discrete and short whistles (a complete description and sonograms can be found in Laiolo et al., 2007).

182 (cloud cover $<10 \%$ and no rain) to avoid potential biases in bird behaviour. Dawn singing 
183 activity of the Dupont's Lark varies with moon phase (authors' own data). Therefore, surveys

184 were carried out on the two days following or preceding full or new moons, to control for the

185 potential effect of moon phase in the analyses. Moon phases were obtained from the Spanish

186 Ministry of Development (http://astronomia.ign.es/web/guest/agenda-astronomica).

\section{Statistical analyses}

All statistical analyses were performed with R v. 3.4.1 (R Development Core Team, 2014) and all results are expressed as mean \pm SE. To analyse the variation of dawn singing or calling activity across the breeding season, we fitted independent Linear Mixed Models for songs and calls. Start time, end time, performance time or total night output were used as response variables. Survey as a continuous variable (" $1 / 2 / 3 / 4 / 5 / 6$ ") was included in models as a fixed effect and site (“Hontanar/Losar/Pinar"), moon phase (“Full/New”), and year (“2013/2014”) as random effects to control for variation owing to site, lunar cycle and inter-annual variations. Linear Mixed Models were fitted using the "Imer" function in the R package "Ime4" (Bates et al., 2015). The degrees of freedom were calculated using the Kenward-Roger method (Kenward \& Roger, 1997). We present models with p-value significance for fixed effects calculated from type III F-tests using the lmerTest package (Kuznetsova et al., 2014).

We also calculated for each survey (pooling sites and years) the Pearson correlation between the total number of songs and calls uttered per male to ascertain whether there was a trade-off between the two types of vocalisations. To evaluate similarity between surveys in the temporal pattern of vocalisations in relation to dawn, we calculated a Pearson correlation matrix between surveys for each type of vocalisation (mean number of songs or calls uttered per male per 5-min period). Each correlation matrix was used as the similarity matrix in a cluster analysis 
206 1973) aimed at identifying groups of surveys with similar dawn activity patterns for songs and

207 calls.

208 Results

209 The only characteristic of singing activity related to the advance of the breeding season

210 was singing output, since total number of songs uttered per male and night significantly

211 increased in later surveys, while singing performance and singing start or ending time did not

212 show a significant trend through surveys (Table 1, Fig. 3). On the contrary, calling activity was

213 strongly related to the advance of the breeding season since calling start time, calling

214 performance period and calling output differed significantly among surveys, while calling end

215 time did not (Table 1). Males initiated calling activity earlier at the end of the breeding season

216 (Fig. 3), despite the fact that they produced significantly more calls and called for more time

217 during the first surveys of the breeding season in comparison to those at the end of the breeding

218 time (Fig. 3 and see Supplementary Table S1). We found a significant negative correlation

219 between the number of songs and the number of calls uttered per male each night during the first

220 survey, which was still significant but less intense in the second survey (Fig. 4 and see

221 Supplementary Table S2). We found no correlation in later surveys, thus showing a decreasing

222 intensity of the correlation between both types of vocalisations as breeding season advanced

223 (Supplementary Table S2).

224 For singing and calling activity, classification analyses identified two periods with 225 different vocalisation distribution before dawn that included in one group the first two surveys 226 and the remaining four surveys in another (Fig. 5). Time patterns of vocal activity before dawn 227 also differed between vocalisation types (Fig. 6). Singing activity showed a symmetrical, bell228 shaped response curve centred in the vocalisation interval, while calling activity peaked between 
229 85-75 minutes before dawn and decreased from that time. Time patterns of both vocalisation

230 types were advanced with respect to dawn in the second group of surveys and were remarkably

231 similar within each group. In addition, calling pattern during the last phase of the breeding

232 season presented a bimodal pattern, with an almost total absence of calls between 30 and 45

233 minutes before dawn, which was lacking in the first two surveys (Fig. 6).

234 Discussion

235 To our knowledge, this is the first study to analyse seasonal patterns of dawn chorus of a 236 passerine using songs and calls with data collected at the same time (but see LaZerte et al., 237 2017). This is also the first study to quantitatively describe the dawn chorus of the Dupont's

238 Lark, an endangered species. We found that dawn seasonal patterns of singing and calling 239 behaviour differed significantly: dawn singing output increased with the advance of the breeding 240 period while dawn calling activity decreased and started earlier as the breeding season advanced.

241 The different seasonal patterns of calls and songs suggest that they serve diverse functions at 242 dawn (Celis-Murillo et al., 2016) and therefore, the use of one or the other vocalisation could 243 lead to different conclusions about dawn chorus function in the studied species.

244 In several passerine species, a pattern of greater dawn singing activity at the beginning of 245 the breeding period has been described, followed by a relaxation after pair formation, in 246 agreement with the hypothesis that dawn song plays a role in mate attraction (e.g. Gil et al., 247 1999; Amrheim et al., 2002; Liu, 2004). Conversely, most of the dawn singing activity 248 parameters analysed in the Dupont's Lark remained constant throughout the breeding season and 249 even song output showed a seasonal increasing trend over time. This temporal pattern does not 250 agree with the patterns expected if the function of songs was to attract females. This suggests 251 that dawn song could play a role in territorial defence in the studied species due to constant dawn 
252 singing activity over time, as has been proposed in other passerines (Olinkiewicz \& Osiejuk,

253 2003; Amrhein et al., 2004; Liu, 2004; Kunc et al., 2005). Previous studies have assumed that

254 dawn singing behaviour in passerines can be used in both male and female interaction contexts,

255 with their functions difficult to ascertain (Slagsvold et al., 1994; Olinkiewicz \& Osiejuk, 2003;

256 Zhang et al., 2016). Both functions have been assigned especially to continuous and loud singing

257 species at dawn, such as the Dupont's Lark, which are able to repel intruders while attracting 258 potential mates or extra-pair mates (Møller, 1991; Naguib et al., 2011).

259 Contrary to dawn song, most of the calling activity parameters analysed changed as the 260 breeding season advanced. The number of calls and the amount of time dedicated to calling 261 decreased as breeding season progressed, especially after the first two surveys. Laiolo et al. 262 (2008) also found that Dupont's Lark calling activity peaked in the first months of the breeding 263 period. This seasonal pattern is compatible with the pattern expected if this vocalisation serves to attract mates, as has been proposed for other passerine birds (e.g. McCallum et al., 1999; Gil et al., 1999; Amrheim et al., 2002; Liu, 2004). In multi-brooded species, vocalisations that attract females are maintained, albeit with reduced intensity. This can be explained as a male response to maintain their mates and quickly mate between successive clutches or if the nest is predated or fails (Mace, 1986; Pärt, 1991). The same explanation could be valid for the Dupont's Lark, as this species has a long breeding season with up to three clutches per year (early March - early July) and high nest predation rates (Herranz et al., 1994; Pérez-Granados et al., 2017b). earlier with the advance of the breeding season. If calls were used for mate attraction, this result may be related to acquiring extra-pair copulations, which usually occur before dawn, a phenomenon well established among larks (Sánchez et al., 2004; Hutchinson \& Griffiths, 2008). 
275 Previous studies on passerines have found that males who began their daily dawn chorus the

276 earliest were the most successful in obtaining extra-pair copulations (Poesel et al., 2006; Dolan,

277 2007). Time relative to dawn of the last call or song uttered did not differ throughout the

278 breeding season, likely because the end of dawn choruses is related to increasing light intensity

279 as sunrise approaches (e.g. Da Silva et al., 2014; York et al., 2014). However, this result may be

280 influenced by the methodology employed, since on some occasions males continued calling after

281 surveys ended, which may have influenced our results.

282 The number of songs and calls uttered per bird each night were strong and negatively

283 related in the first survey, but this relationship weakened with the advance of the breeding season

284 and was non-existent from the third survey onwards. This pattern could be the consequence of a

285 trade-off between territorial defence and mate attraction (Hasselquist \& Bensch, 1991; Slagsvold

286 et al., 1994), because males may utilise different acoustic strategies (calling or singing) when

287 attracting mates or defending territories (Zhang et al., 2016). This trade-off may be enhanced in

288 species, like Dupont's Lark, that concentrate vocal activity in short periods in the daily cycle. A

289 larger proportion of unpaired males at the first stage of the breeding season would make this

290 trade-off more apparent at that time, as these males would invest more time in calling for

291 attracting females at the cost of reducing song output, while after pairing more efforts would be

292 devoted to singing.

293 We found different daily patterns at dawn for singing and calling activity. In general,

294 Dupont's Lark uttered calls mostly during the first 30 minutes of dawn choruses with songs

295 being the commonest vocalisation onwards. The mean daily pattern of singing and calling

296 activity were similar along the breeding season, but that pattern was more advanced in the later

297 surveys, with birds singing and calling earlier in time. This definite daily pattern together with 
298 seasonal differences found between vocalisation types support our assumption that calls and 299 songs may serve diverse functions in the studied species, as has been proposed for other 300 passerines (Celis-Murillo et al., 2016). According to hypothetical functions assumed for dawn 301 singing and dawn calling in the studied species, our results suggest that males may dedicate more 302 time to mate attraction at the beginning of dawn choruses, under low-light conditions, and to 303 territorial defence from that moment on. These different patterns may also reflect a trade-off 304 between singing and calling within each period before dawn, as the peak in singing is associated with a decrease in calling. The temporal pattern of calling becomes bimodal from the third survey onwards, as calling activity ceases completely between 45 and 35 minutes before dawn, just after the peak in signing. Song output increases as season advances, and particularly after the

308 309 second survey, and thus cessation of calling could be due to increasing efforts in singing.

\section{Conclusions}

In this study, we found evidence that dawn singing and calling activity in Dupont's Lark present different temporal patterns of activity, both along the breeding season and in the period before dawn, when most of the vocal activity of this species occurs. These different patterns suggest that calls and songs in the Dupont's Lark may have functions different to those expected. However, experimental studies are needed to obtain conclusive results about the concrete function of each vocalisation type in the studied species. To unravel the functions of these vocalisations, the next step should be to develop experimental studies testing responses of males and females to songs and calls that would provide additional insight into dawn chorus signalling functions in the Dupont's Lark. Nevertheless, our results highlight that the type of vocalisation used is an important factor to consider when seasonal changes of vocal activity are studied, and thus previous interpretations made for birds' dawn choruses may need to be re-evaluated in light 
321 of the type of vocalisation analysed. We encourage researchers to clearly describe the type of

322 vocalisation used in future studies.

323

\section{Acknowledgements}

325 We are grateful to three anonymous reviewers whose comments helped to improve the manuscript. We wish to thank the Servicio de Vida Silvestre of Conselleria d'Infraestructures, Territori i Medi Ambient (Generalitat Valenciana) and Juan Jiménez for supporting our work. We thank Sarah Young for help with the written English.

\section{References:}

331 Allen, F. H. 1913. More notes on the morning awakening. Auk, 30: 229-235.

Amrhein, V., \& Erne, N. 2006. Dawn singing reflects past territorial challenges in the winter wren. Animal Behaviour, 71(5): 1075-1080.

Amrhein, V., Korner, P., \& Naguib, M. 2002. Nocturnal and diurnal singing activity in the nightingale: correlations with mating status and breeding cycle. Animal Behaviour, 64(6): 939944.

Amrhein, V., Kunc, H. P., \& Naguib, M. 2004. Seasonal patterns of singing activity vary with time of day in the nightingale (Luscinia megarhynchos). The Auk, 121(1): 110-117. Traba, J. 2017. ¿Son los mejores machos los que más defienden el territorio? Comportamiento territorial de los machos de alondra ricotí durante el periodo reproductor en la ZEPA Altos de

342 Barahona, Soria. Póster. Actas del XXIII Congreso Español de Ornitología. Pp. 140. 2-5 343 Noviembre, Badajoz, España. 
344 Bates, D., Maechler, M., Bolker, B., \& Walker, S. 2015. Ime4: Linear mixed-effects models using 345 Eigen and S4. R package version 1.1-7. 2014. Institute for Statistics and Mathematics of WU 346 website. http://CRAN. R-project. org/package= lme4. Accessed March, 18.

347 Catchpole, C. K., \& Slater, P. J. 2008. Bird song: biological themes and variations. 2nd ed. 348 Cambridge university press.

349 Celis-Murillo, A., Stodola, K. W., Pappadopoli, B., Burton, J. M., \& Ward, M. P. 2016. Seasonal 350 and daily patterns of nocturnal singing in the Field Sparrow (Spizella pusilla). Journal of 351 Ornithology, 157(3): 853-860.

352 Cramp, S. 1988. The Birds of the Western Palearctic. Vol. 5. Oxford University Press, New 353 York.

354 Da Silva, A., Samplonius, J. M., Schlicht, E., Valcu, M., \& Kempenaers, B. 2014. Artificial 355 night lighting rather than traffic noise affects the daily timing of dawn and dusk singing in 356 common European songbirds. Behavioral Ecology, aru103.

357 Dolan, A. C., Murphy, M. T., Redmond, L. J., Sexton, K., \& Duffield, D. 2007. Extrapair 358 paternity and the opportunity for sexual selection in a socially monogamous passerine. 359 Behavioral Ecology, 18(6): 985-993.

360 Eriksson, D., \& Wallin, L. 1986. Male bird song attracts females - a field experiment. 361 Behavioral Ecology and Sociobiology, 19(4): 297-299.

362 Garamszegi, L. Z., Pavlova, D. Z., Eens, M., \& Møller, A. P. 2006. The evolution of song in 363 female birds in Europe. Behavioral Ecology, 18(1): 86-96.

364 Gil, D., Graves, J. A., \& Slater, P. J. 1999. Seasonal patterns of singing in the willow warbler: 365 evidence against the fertility announcement hypothesis. Animal Behaviour, 58(5): 995-1000. 
366 Grava, T., Grava, A., \& Otter, K. A. 2009. Supplemental feeding and dawn singing in black367 capped chickadees. Condor, 111: 560-564.

368 Grava, A., Otter, K. A., Grava, T., LaZerte, S. E., Poesel, A., \& Rush, A. C. 2013. Character 369 displacement in dawn chorusing behaviour of sympatric mountain and black-capped chickadees.

370

371

372

373

374

375 376

377 378

379

380

381

382

383

384 385

386

387

Animal Behaviour, 86(1): 177-187.

Hasselquist, D., \& Bensch, S. 1991. Trade-off between mate guarding and mate attraction in the polygynous great reed warbler. Behavioral Ecology and Sociobiology, 28(3): 187-193.

Herranz, J., Manrique, J., Yanes, M., \& Suárez, F. (1994). The breeding biology of Dupont's lark, Chersophilus duponti, in Europe. Avocetta, 18(2): 141-146.

Hutchinson, J., \& Griffith, S. C. 2008. Extra-pair paternity in the Skylark Alauda arvensis. Ibis, 150(1): 90-97.

Kacelnik, A., \& Krebs, J.R. 1983. The dawn chorus in the great tit (Parus major): proximate and ultimate causes. Behaviour, 83: 287-309.

Kenward, M. G., \& Roger, J. H. (1997). Small sample inference for fixed effects from restricted maximum likelihood. Biometrics, 983-997.

Kunc, H.P., Amrhein, V., \& Naguib, M. 2005. Seasonal variation in dawn song characteristics in the common nightingale. Animal Behaviour, 70(6): 1265-1271.

Kuznetsova, A., Brockhoff, P.B., Christensen, R.H.B. 2014. ImerTest: Tests for random and fixed effects for linear mixed effect models (lmer objects of lme4 package). R package version $2.0-11$

Laiolo, P. 2008. Characterizing the spatial structure of songbird cultures. Ecological Applications, 18(7): 1774-1780. 
388 Laiolo, P., Tella, J.L. 2005. Habitat fragmentation affects culture transmission: patterns of song 389 matching in Dupont's lark. Journal of Applied Ecology, 42(6): 1183-1193.

390 Laiolo, P., \& Tella, J.L. 2006. Landscape bioacoustics allow detection of the effects of habitat 391 patchiness on population structure. Ecology, 87(5): 1203-1214.

392 Laiolo, P., Vögeli, M., Serrano, D., \& Tella, J.L. 2005. Two new calls from the Dupont's Lark 393 Chersophilus duponti and imitations by other Alaudids: ecological and monitoring implications. 394 Ardeola, 52(1): 167-172.

395 Laiolo, P., Vögeli, M., Serrano, D., \& Tella, J.L. 2007. Testing acoustic versus physical marking: 396 two complementary methods for individual-based monitoring of elusive species. Journal of 397 Avian Biology, 38(6): 672-681.

398 Laiolo, P., Vögeli, M., Serrano, D., \& Tella, J.L. 2008. Song diversity predicts the viability of 399 fragmented bird populations. PLoS One, 3(3), e1822.

400 LaZerte, S. E., Otter, K. A., \& Slabbekoorn, H. 2017. Mountain chickadees adjust songs, calls 401 and chorus composition with increasing ambient and experimental anthropogenic noise. Urban 402 Ecosystems, 1-12.

403 Lee, J. G. H., MacGregor-Fors, I., \& Yeh, P.J. 2017. Sunrise in the city: disentangling drivers of 404 the avian dawn chorus onset in urban greenspaces. Journal of Avian Biology, 48(7): 955-964.

405 Liu, W.C. 2004. The effect of neighbours and females on dawn and daytime singing behaviours 406 by male chipping sparrows. Animal Behaviour, 68(1): 39-44.

407 Liu, W.C., \& Kroodsma, D.E. 2007. Dawn and daytime singing behavior of chipping sparrows 408 (Spizella passerina). Auk, 124: 44-52.

409 Mace, R. 1986. Importance of female behaviour in the dawn chorus. Animal Behaviour, 34(2): $410 \quad 621-622$. 
411 Mace, R. 1987. The dawn chorus in the great tit Parus major is directly related to female 412 fertility. Nature, 330: 745-746.

413 Marini, K.L., Reudink, M.W., LaZerte, S.E., \& Otter, K.A. 2017. Urban mountain chickadees 414 (Poecile gambeli) begin vocalizing earlier, and have greater dawn chorus output than rural 415 males. Behaviour, 154(12): 1197-1214.

416 Marler, P. 2004. Bird calls: their potential for behavioral neurobiology. Annals of the New York 417 Academy of Sciences, 1016(1): 31-44.

418 McCallum, D.A., Grundel, R., Dahlsten, D.L. 1999. Mountain chickadee (Poecile gambeli). In: 419 Poole A (ed) The birds of North America online. Cornell Laboratory of Ornithology, Ithaca.

420 Møller, A.P. 1988. Spatial and temporal distribution of song in the yellowhammer Emberiza 421 citrinella. Ethology, 78(4): 321-331.

422 Møller, A.P. 1991. Why mated songbirds sing so much: mate guarding and male announcement 423 of mate fertility status. American Naturalist, 138(4): 994-1014.

424 Murphy, M. T., Sexton, K., Dolan, A. C., \& Redmond, L. J. 2008. Dawn song of the eastern 425 kingbird: an honest signal of male quality? Animal Behaviour, 75(3): 1075-1084.

426 Naguib, M., Kunc, H.P., Sprau, P., Roth, T., \& Amrhein, V. 2011. Communication networks and 427 spatial ecology in Nightingales. Adv Stud Behav, 43: 239-271.

428 Naguib, M., van Rooij, E. P., Snijders, L., \& Van Oers, K. 2016. To sing or not to sing: seasonal 429 changes in singing vary with personality in wild great tits. Behavioral Ecology, 27(3): 932-938.

430 Odom, K.J., \& Benedict, L. 2018. A call to document female bird songs: Applications for diverse 431 fields. The Auk, 135(2): 314-325.

432 Olinkiewicz, A., \& Osiejuk T.S. 2003. Effect of time of season and neighbours on singing 433 activity in the Corn Bunting Miliaria calandra. Acta Ornithologica, 38: 117-122. 
434 Pärt, T. 1991. Is dawn singing related to paternity insurance? The case of the collared flycatcher. 435 Animal Behaviour, 41(3): 451-456.

436 Pérez-Granados, C., \& López-Iborra, G.M. 2013. Census of Breeding Birds and Population 437 Trends of the Dupont's Lark Chersophilus duponti in Eastern Spain. Ardeola, 60(1): 143-150.

438 Pérez-Granados, C., \& López-Iborra, G.M. 2015. Baja dispersión adulta y baja tasa de recaptura 439 juvenil de la alondra ricotí (Chersophilus duponti) en el Rincón de Ademuz (Valencia). XX 440 Congreso de Anilladores. 10 de octubre, Ceuta. Oral communication.

441 Pérez-Granados, C., Osiejuk, T., \& López-Iborra, G. M. 2016. Habitat fragmentation effects and 442 variations in repertoire size and degree of song sharing among close Dupont's Lark Chersophilus 443 duponti populations. Journal of Ornithology, 157: 471-482.

444 Pérez-Granados, C., López-Iborra, G.M., Seoane, J. 2017a. A multi-scale analysis of habitat 445 selection in peripheral populations of the endangered Dupont's Lark Chersophilus duponti. Bird 446 conservation International, 27(3): 398-413.

447 Pérez-Granados, C., López-Iborra, G.M., Garza, V., Traba, J. 2017b. Breeding biology of the 448 endangered Dupont's Lark Chersophilus duponti in two separate Spanish shrub-steppes. Bird 449 Study, 64(3): 328-338.

450 Poesel, A., Foerster, K., \& Kempenaers, B. 2001. The dawn song of the blue tit Parus caeruleus 451 and its role in sexual selection. Ethology, 107(6): 521-531.

452 Poesel, A., Kunc, H. P., Foerster, K., Johnsen, A., \& Kempenaers, B. 2006. Early birds are sexy: 453 male age, dawn song and extrapair paternity in blue tits, Cyanistes (formerly Parus) caeruleus. 454 Animal Behaviour, 72(3): 531-538.

455 R Development Core Team. 2014. R: A Language and Environment for Statistical Computing. R 456 Foundation for Statistical Computing. Vienna, Austria. 
457 Sánchez, A.M., Herranz, J., Martínez, J.G., \& Suárez, F. 2004. Extra-pair paternity in Short-toed 458 and Lesser Short-toed Larks Calandrella brachydactyla and C. rufescens. Bird Study, 51(3): $459 \quad 278-279$.

460 Slagsvold, T., Dale, S., \& Sætre, G.P. 1994. Dawn singing in the great tit (Parus major): mate 461 attraction, mate guarding, or territorial defence? Behaviour, 131(1): 115-138.

462 Sneath, P.H., \& Sokal, R.R. 1973. Numerical taxonomy. Freeman, San Francisco. Staicer, C.A., 463 Spector, D.A. \& Horn, A.G. 1996. The dawn chorus and other diel patterns in acoustic 464 signaling. In: Ecology and Evolution of Acoustic Communication in Birds. (Kroodsma, D. E., 465 Miller, E. H., eds). Cornell Univ. Press, New York, NY, pp. 426-453.

466 Stanley, C.Q., Walter, M.H., Venkatraman, M.X., \& Wilkinson, G.S. 2016. Insect noise 467 avoidance in the dawn chorus of Neotropical birds. Animal Behaviour, 112: 255-265.

468 Stowell, D., Gill, L., \& Clayton, D. 2016. Detailed temporal structure of communication 469 networks in groups of songbirds. Journal of the Royal Society Interface, 13(119), 20160296.

470 Vögeli, M., Serrano, D., Pacios, F., \& Tella, J.L. 2010. The relative importance of patch habitat 471 quality and landscape attributes on a declining steppe-bird metapopulation. Biological 472 Conservation, 143(5), 1057-1067.

473 Wang, G., Harpole, C.E., Trivedi, A.K., \& Cassone, V.M. 2012. Circadian regulation of bird 474 song, call, and locomotor behavior by pineal melatonin in the zebra finch. Journal of Biological 475 Rhythms, 27(2): 145-155.

476 Webb, W. H., Brunton, D. H., Aguirre, J. D., Thomas, D. B., Valcu, M., \& Dale, J. 2016. Female 477 song occurs in songbirds with more elaborate female coloration and reduced sexual 478 dichromatism. Frontiers in Ecology and Evolution, 4: 22.

479 Wright, H. W. 1912. Morning awakening and even-song. Auk, 29: 307-327. 
480 York, J.E., Young, A.J., \& Radford, A.N. 2014 Singing in the moonlight: dawn song 481 performance of a diurnal bird varies with lunar phase. Biology Letters, 10: 20130970.

482 Zann, R. 1990. Song and call learning in wild zebra finches in south-east Australia. Animal 483 Behaviour, 40(5): 811-828.

484 Zhang, V. Y., Celis-Murillo, A., \& Ward, M. P. 2016. Conveying information with one song 485 type: changes in dawn song performance correspond to different female breeding stages. 486 Bioacoustics, 25(1): 19-28. 


\section{Table $\mathbf{1}$ (on next page)}

Test of significance of the survey period as fixed effect in the GLMMs for different response variables describing singing and calling behaviour of the Dupont's Lark at dawn. 


\begin{tabular}{lccc|ccc}
\hline & \multicolumn{3}{c|}{ Songs } & \multicolumn{3}{c}{ Calls } \\
\hline Response variable & Sum Sq & F & $\operatorname{Pr}(>\mathrm{F})$ & Sum Sq & F & $\operatorname{Pr}(>\mathrm{F})$ \\
Start time & 72.65 & 1.32 & 0.252 & 902.46 & 45.83 & $<0.001$ \\
End time & 102.92 & 0.90 & 0.343 & 1.65 & 0.034 & 0.854 \\
Performance time & 1.38 & 0.22 & 0.639 & 96.28 & 17.58 & $<0.001$ \\
Output & 6705.3 & 4.48 & 0.036 & 25704 & 21.70 & $<0.001$ \\
\hline
\end{tabular}

1 
Figure 1

Location of the sampling stations in the three studied sites, and sampling station procedure. Song activity was registered individually for each Dupont's Lark male, according to their different distance and location to observer.

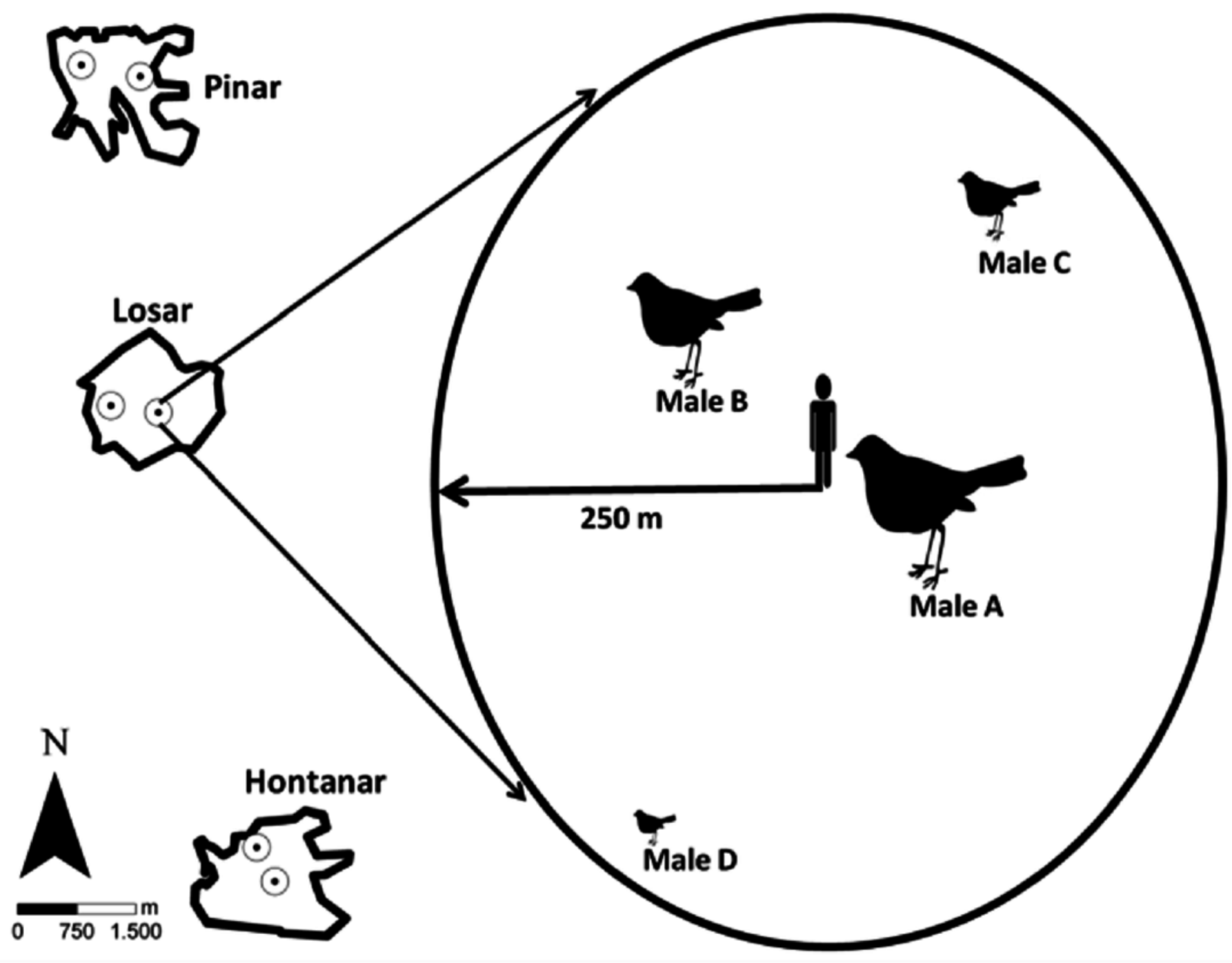


Figure 2

Sonogram of a typical Dupont's Lark song in the study area.

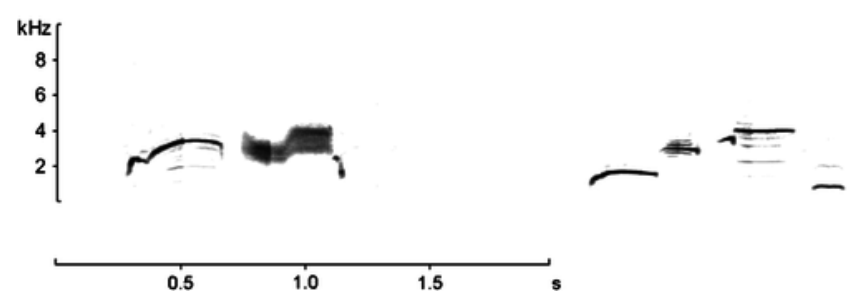

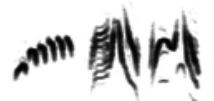

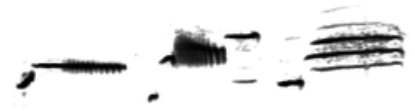




\section{Figure 3}

Mean \pm SE singing and calling activity at dawn of Dupont's Lark during the breeding cycle of the years 2013 and 2014 at Rincón de Ademuz (eastern Spain).

Vocal activity was monitored in six surveys, performed fortnightly from late March (First Survey) to early June (Sixth Survey). Start time (A, minutes before sunrise when the first song or call was uttered), End time ( $B$, minutes before or after sunrise when last song or call was produced), Performance time (C, total of 5-min intervals that each bird was active) and Output ( $D$, total number of songs or calls uttered per male), are expressed for dawn singing activity (filled circles) and dawn calling activity (empty circles).
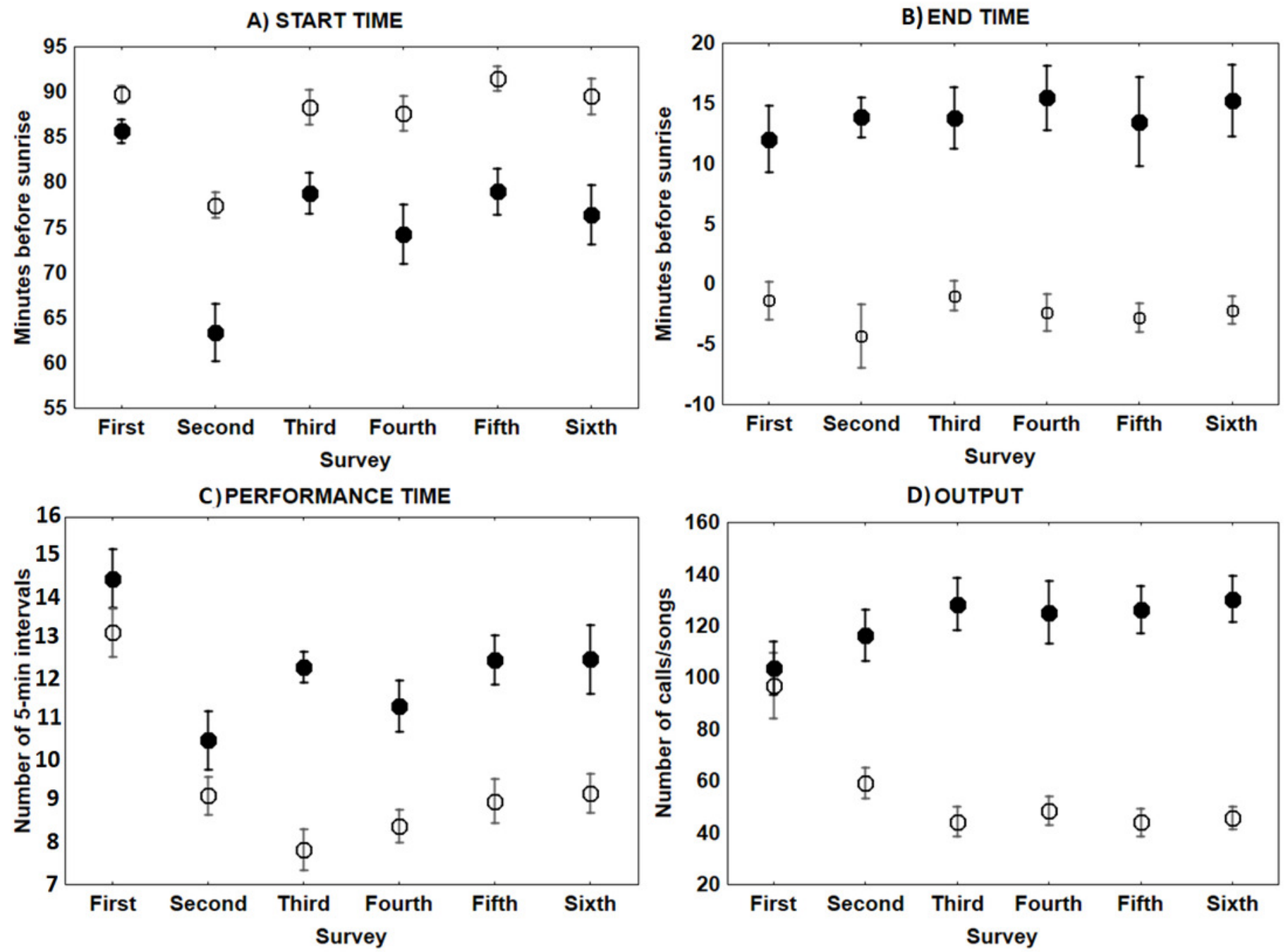

D) OUTPUT

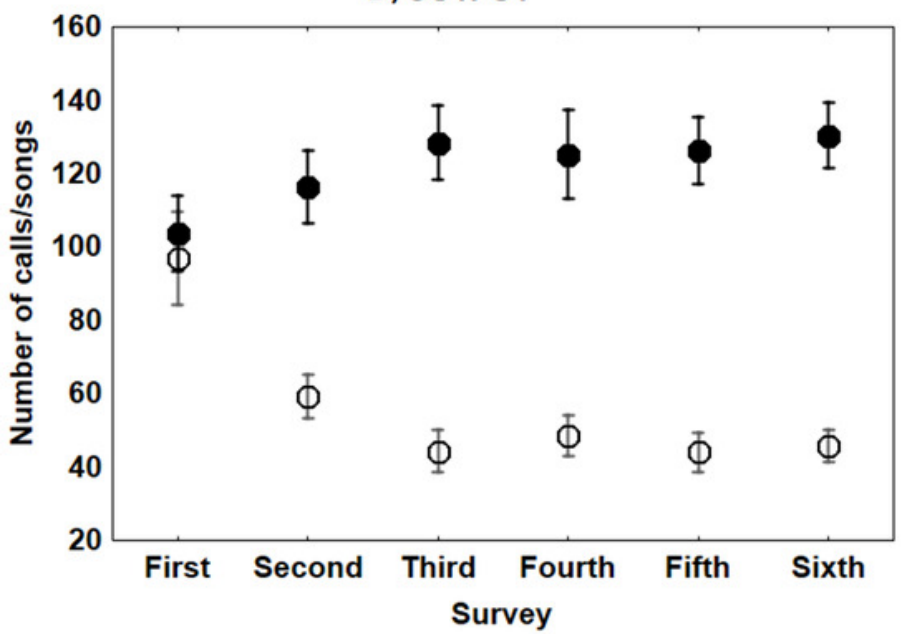




\section{Figure 4}

Linear relationships between the number of songs and calls uttered per each Dupont's Lark male and survey (data of 2013 and 2014 pooled) at Rincón de Ademuz (eastern Spain).

Vocal activity was monitored in six surveys, performed fortnightly from late March (First Survey) to early June (Sixth Survey). Surveys with significant Pearson's correlations are represented with filled symbols and their $R^{2}$ value can be found in legend (see complete analyses in Supplemental Table S2).

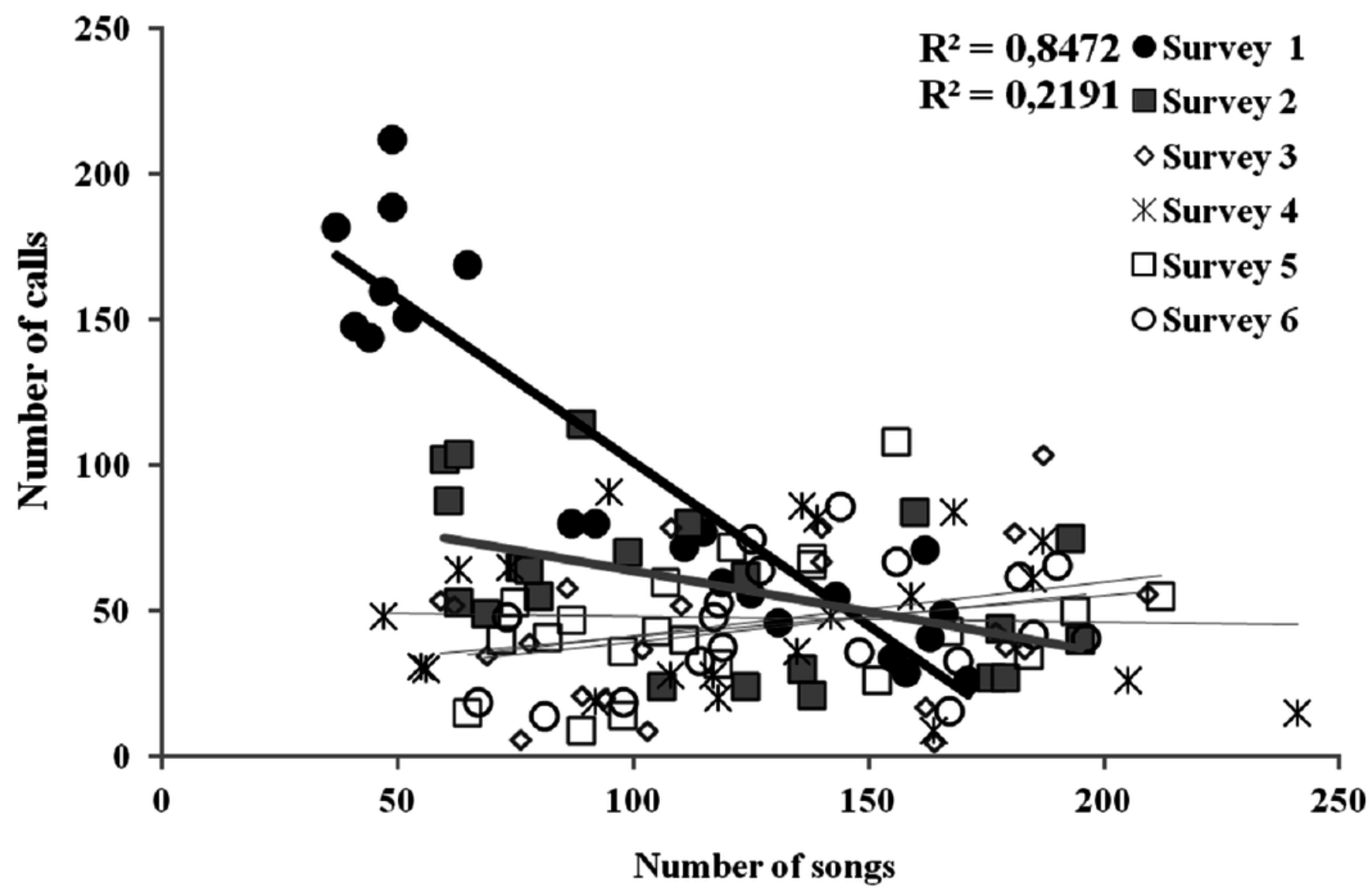


Figure 5

Similarity in the distribution of each type of vocalisations (A: songs; B: calls) during Dupont's Lark dawn choruses.

Dendrogram resulted from hierarchical cluster analyses using complete linkage. Pearson's correlation between surveys in the mean number of songs or calls uttered per male per 5min period was used as similarity measure. Correlations were converted to distances computed as 1.0 minus Pearson $r$.
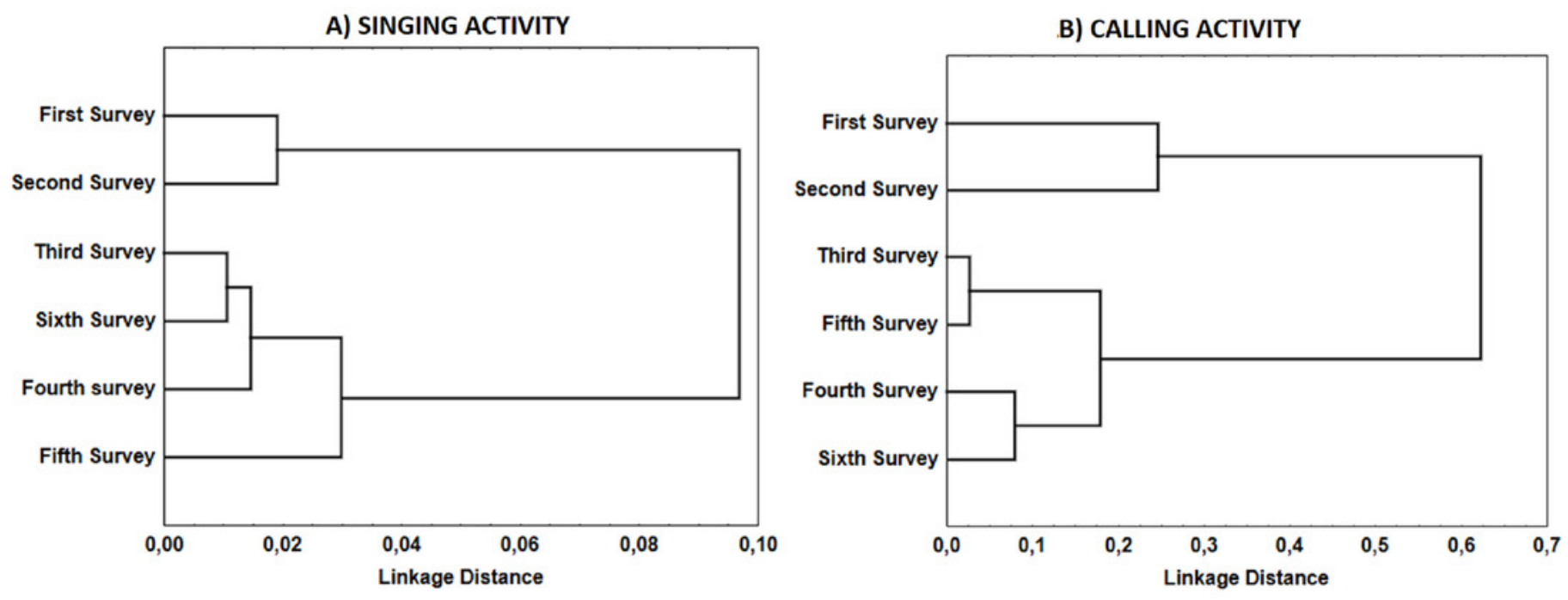


\section{Figure 6}

Dawn vocal activity pattern of Dupont's Lark during the breeding cycle of the years 2013 and 2014 at Rincón de Ademuz (eastern Spain).

Vocal activity was monitored in six surveys, performed fortnightly from late March (First Survey) to early June (Sixth Survey). Vocal activity is expressed as the mean number of songs or calls uttered per male per 5-min interval. Mean singing (filled line) and calling (dotted line) activity in the first (A) and the second (B) periods identified by cluster analysis (see Fig. 4). Mean daily pattern of singing (C) and calling (D) activity for the surveys included in the periods defined in Fig. 4.
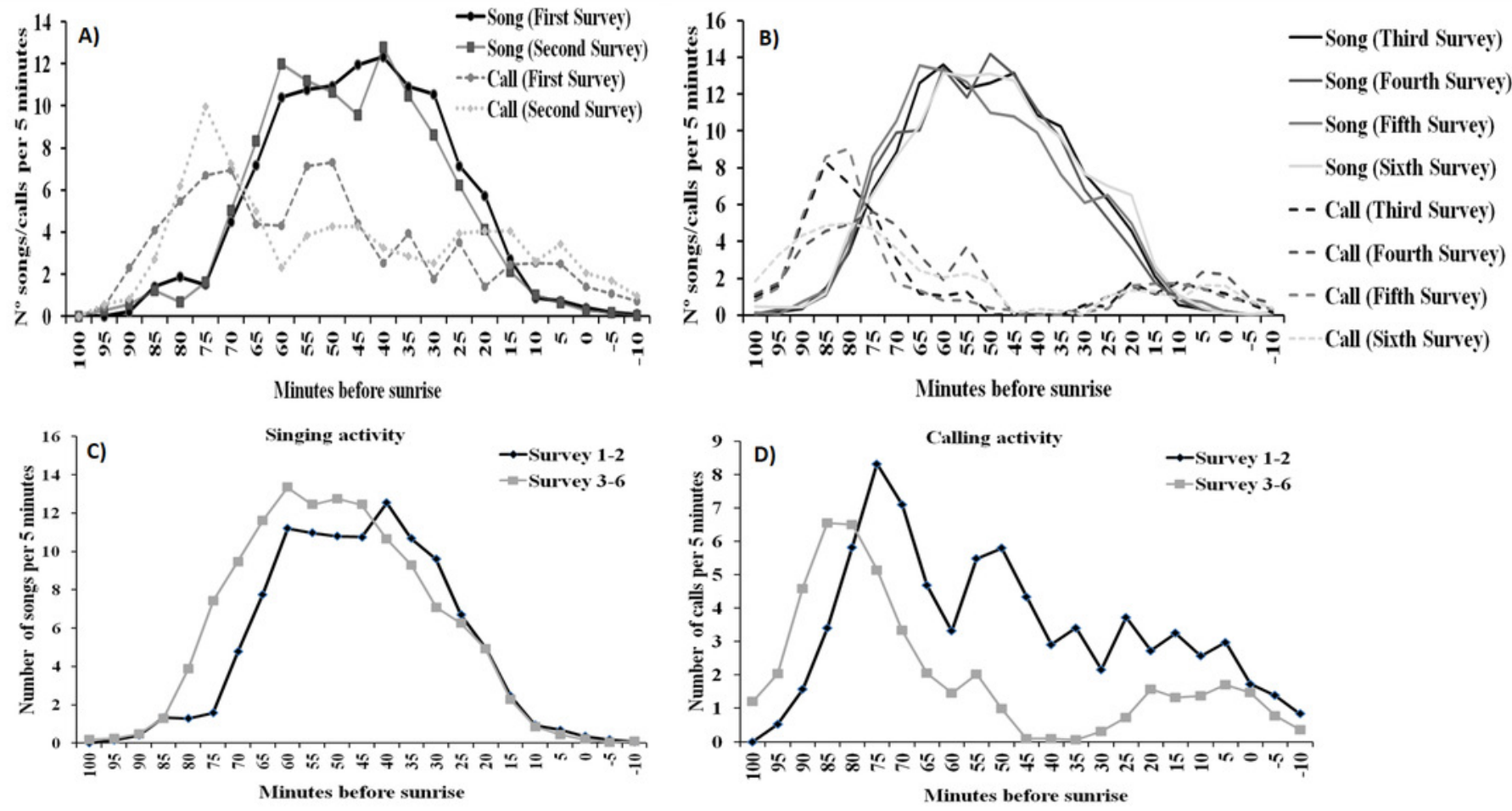